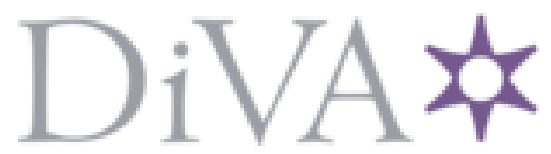

http://www.diva-portal.org

\title{
Postprint
}

This is the accepted version of a paper presented at 2014 IEEE 14th International Conference on Advanced Learning Technologies (ICALT), 7-10 July 2014, Athens.

Citation for the original published paper:

Zbick, J., Jansen, M., Milrad, M. (2014)

Towards a web-based framework to support end-user programming of mobile learning activities. In: 2014 IEEE 14th International Conference on Advanced Learning Technologies (ICALT) (pp. 204-208). IEEE Press

IEEE International Conference on Advanced Learning Technologies http://dx.doi.org/10.1109/ICALT.2014.66

N.B. When citing this work, cite the original published paper.

C2014 IEEE. Personal use of this material is permitted. However, permission to reprint/republish this material for advertising or promotional purposes or for creating new collective works for resale or redistribution to servers or lists, or to reuse any copyrighted component of this work in other works must be obtained from the IEEE

Permanent link to this version:

http://urn.kb.se/resolve?urn=urn:nbn:se:lnu:diva-36438 


\section{Towards a web-based framework to support end-user programming of mobile learning activities}

\author{
Janosch Zbick \\ Department of Media Technology \\ Linnaeus University, Sweden \\ janosch.zbick@lnu.se
}

\author{
Marc Jansen \\ Department of Media Technology \\ Linnaeus University, Sweden \\ marcbjorn.jansen@1nu.se
}

\author{
Marcelo Milrad \\ Department of Media Technology \\ Linnaeus University, Sweden \\ marcelo.milrad@lnu.se
}

\begin{abstract}
This paper describes the design and development stages of a web-based framework, aiming to support the creation of mobile applications within the context of mobile learning. The suggested approach offers the opportunity to deploy and execute these applications on mobile devices. This web-based solution additionally offers the possibility to visualize the data collected by the mobile applications in a webbrowser. Despite previous research efforts carried out in this domain, few of the projects have addressed these processes from a purely web-based perspective. Currently, a prototype of an authoring tool for creating mobile data collection applications is already implemented. In order to integrate and validate this solution in everyday educational settings, we are collaborating with a network of high schools. On the basis of workshops with teachers we will carry out, refinements and requirements for further enhancements will be collected and will be used to guide our coming efforts.
\end{abstract}

Mobile Learning; web-based framework; end-user programming; authoring tool

\section{INTRODUCTION}

The demand for digitally supported education and the adoption of information and communication technologies (ICT) in schools increased rapidly in recent years [1]. In line with these trends, one of the aims of our research is to increase the awareness of teaching practices and the role of authenticity in teaching via the introduction of web, mobile and sensor technologies. We are collaborating with a network of high schools in Southeast of Sweden to foster the introduction of a one-to-one distribution, one computer per student, which offers new opportunities to support teaching and learning. Studies show that the ability of teachers to further elaborate and improve their teaching methods and practices by using the latest development in ICT is essential to maintain and increase the quality of teaching and is therefore an important subject for research [2].

The availability of mobile devices can, at least initially, stimulate and motivate students to perform learning activities, but the challenge lies in creating authentic activities in a variety of settings that motivate students to learn. Previous research found that authenticity can stimulate students' motivation and therefore it provides a valuable opportunity to stimulate learning [3]. Furthermore, [4] show in their work that authenticity can be achieved by tasks that lead to a response that is relevant to the learners interests or is relevant to ongoing topics in the society.
Modern mobile technologies can be effectively used to support authentic learning activities. Activities that do not take place at a fixed predetermined location and the learner takes advantage of the technologies mentioned above, thus offering new learning opportunities, we can then refer to those activities as mobile learning activities [5]. Mobile technologies can facilitate learning outside the classroom to enhance the learning experience [6] and learning materials are no longer limited to traditional materials like books [7]. A challenge that arises with the growing role of mobile technologies in the field of education is the importance to provide end-users, in particular teachers, with the possibility to author and deploy their own mobile applications [8] as they usually do not have the technical and programming skills to develop mobile applications suiting their requirements. Therefore, this latest issue becomes a central challenge for the field of Technology-Enhanced Learning (TEL). Thus, one area of concern developers and researchers are exploring is how to give end-users the possibility to create and author their own mobile applications.

The rapid and constant evolution of web and mobile technologies brings new opportunities to developers and researchers in the process of creating innovative mobile applications. Not only high definition cameras but also positioning technologies and other sensors as well as ubiquitous Internet access became standard features of modern mobile devices. In spite of the multiple benefits that this setup offers, a major challenge for developers of mobile applications arises due to the huge fragmentation of the market of mobile devices and their operating systems. Emerging web technologies, e.g. HTML5 and new JavaScript approaches, provide some of the requirements that can be used to address the challenges mentioned above [9]. In the rest of the paper, we motivate the need of our research and proceed by presenting the different components of our web-based framework. Thereafter, we describe its integration into school activities followed by our validation plans and directions of future work.

\section{MOTIVATION AND RESEARCH QUESTIONS}

The different conditions and lines of argumentation mentioned above lead to the idea of a web-based framework to support the creation of mobile learning applications, the automated deployment and the web-based execution of those. This approach can potentially offer the possibility for end-users to easily design learning tasks within a web-
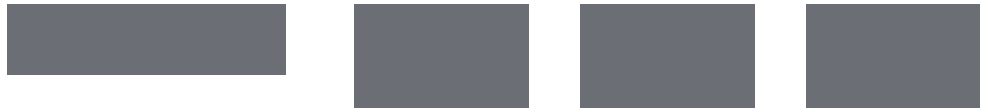
browser, which also can be executed on a mobile webbrowser without the concern of the fragmented mobile device market. To be able to support students in the debriefing and reflection processes after the learning activity, the framework should also offer a visualization tool for presenting and sharing the data collected by the students. This visualization tool additionally should provide some data analysis features to support the processes mentioned above. The idea behind visualizing collected data is to enable students to easily perform visual exploration and analysis of data to facilitate the understanding of a particular phenomenon and also to communicate findings [10].

To tackle the problem about interoperability, the designed mobile application should be platform-independent to deal with the needs of the fragmented market. This means, the deployed mobile applications should run on a variety of mobile devices and operating systems as a platformindependent application.

Projects like [11-14] present an initial overview of similar approaches to design or execute mobile learning tasks. However, there is a lack of supporting this flow in a cross-platform approach that supports the whole workflow from designing, deploying, executing and visualizing. Only the work carried out by [11] and [13] offers the possibility to author mobile learning activities. Other projects do not tackle the issue of end-user programming but offer a mobile application to execute mobile learning activities. However, even the projects that enable end-users to design their own mobile application do not tackle the issue of interoperability. None of the work mentioned above offer a platformindependent solution for the mobile application and only the work by [13] supports the flow from designing a learning scenario over the mobile execution to the visualization of collected data. However, this approach needs additional software installed and has no platform independent solution for the mobile application or the designing of it. Based on the ideas discussed above we formulated the following research questions:

- RQ1: How can a framework be designed to enable the creation and automated deployment of mobile learning applications?

- RQ2: What technologies need to be used to foster a cross-platform solution to support the workflow from designing, deploying, executing and visualizing?

\section{TOWARDS A WEB-BASED FRAMEWORK}

As mentioned earlier in the previous sections, there is a need for a framework that supports mobile learning activities having in mind the latest developments related to ICT infrastructure in schools. In order to take full advantage of the available technological setup, it is necessary to provide support for teachers to compose their own learning applications for mobile devices. Outdoor activities of the kind of field trips are very well suited candidates for using mobile technologies as support. In [15], the authors state that a learning activity outside the classroom, a field trip, can be divided in three phases: The pre-trip phase, where the preparation of a trip takes place, the trip itself and the post- trip phase, where the debrief of the trip is conducted. The pre-trip phase usually takes place in the classroom and includes the planning of the trip as well as other preparations. The trip itself is located outside the classroom and the post-trip phase can either be carried out to the field or takes place in the classroom. To tackle RQ1, we are proposing a framework to provide technological support throughout all three phases by using a web-based approach, including an authoring tool to support the planning and designing of learning activities outside the classroom, a repository to store the collected data and a web-based visualization tool. The activities created for the outdoor tasks are deployed as mobile web-applications and are accessible via a mobile web-browser. Table 1 gives an overview related to the different phases and their location and the components of the proposed framework to support each phase.

\begin{tabular}{c|ccc|}
\multirow{2}{*}{ Phase } & \multicolumn{2}{c}{ Table 1. Phases and components } & \\
Actors & Location & Component \\
\hline trip & teacher & classroom & $\begin{array}{c}\text { authoring } \\
\text { tool }\end{array}$ \\
post-trip & students & $\begin{array}{c}\text { outside in } \\
\text { the field }\end{array}$ & $\begin{array}{c}\text { mobile } \\
\text { application }\end{array}$ \\
& $\begin{array}{c}\text { teacher, } \\
\text { student }\end{array}$ & classroom & $\begin{array}{c}\text { visualization } \\
\text { tool }\end{array}$
\end{tabular}

It is important for the teacher to be able to access the authoring tool from multiple computers, regardless of the available operating system. Thus, to tackle the RQ2, we suggest a web-based solution to offer access to the components from every device with a modern web-browser installed while no installation of any additional software is required. Furthermore, the mobile application should be based on pure HTML5 and JavaScript in order to assure the compatibility to a wide range of modern mobile devices, offering access to the application with the mobile webbrowser. A mobile web-application also guarantees compatibility to future mobile devices and operating systems. All these aspects have been carefully considered in order to make the adoption of technology easier for educators, as it affects the way teachers introduce new technologies into their everyday practices [16].

As presented in [17], all three components of the framework described above are realized in pure HTLM5 and JavaScript and as a backbone technology NodeJS ${ }^{1}$ is used. Since the characteristics of NodeJS allow designing scalable applications, it fits our needs. The non-blocking I/O design and the single threaded event loop of NodeJS provide the advantageous architecture for developing scalable webapplications.

JavaScript is used as a key technology in every part of the framework and therefore all data is transferred as JSON objects. Since JSON is the common interface standard in web-development, it provides the perfect requirement to

\footnotetext{
${ }^{1}$ http://nodejs.org
} 
tackle the desired interoperability. The MongoDB ${ }^{2}$ database accepts JSON objects as an input and therefore fits perfectly in the proposed design and thus is used for data persistence. In addition, a website including different views serves as a common access point throughout all the phases of the described outdoor activities. Teachers can gain access to the authoring tool through this website, students have access to the mobile application on the website and the visualization tool is available for both parties. Figure 1 provides an overview of the different components of the proposed framework while Figure 2 gives an overview of the used technologies.

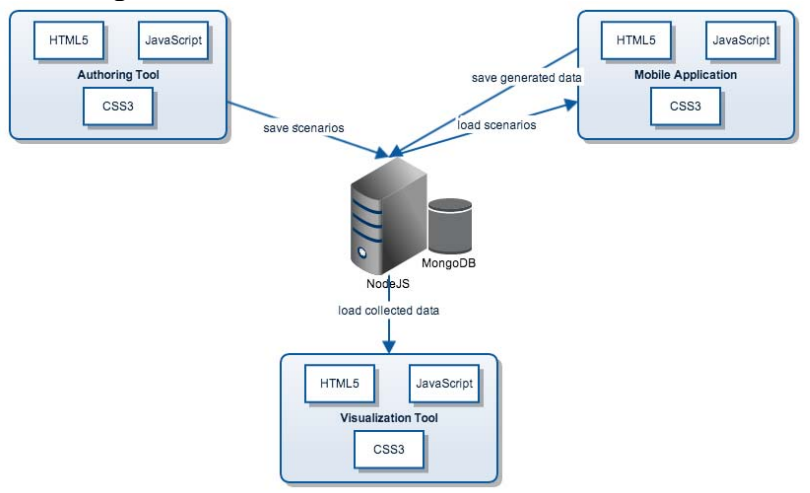

Figure 1. Components of the framework

As shown in Figure 2 additional NodeJS modules are used: Mongoose for the connection to the MongoDB database; Jade, a template engine to render HTML; and express, a web-application framework to build multi-page web-applications.

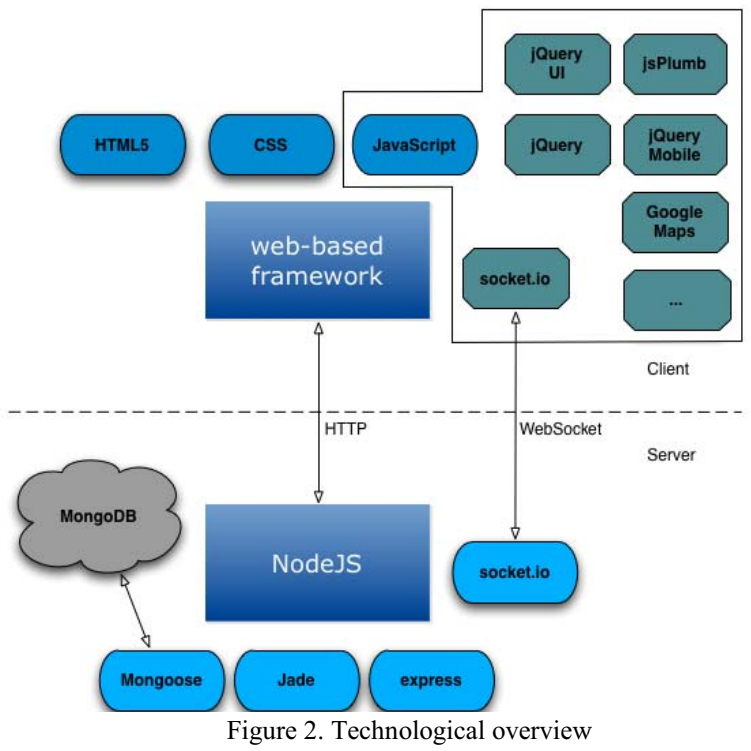

On the client-side, supplementary JavaScript libraries like jQuery are used to foster a cross-platform mobile application. The general communication happens via HTTP

\footnotetext{
${ }^{2}$ http://www.mongodb.org/
}

with the exception of the real time data visualization, which will be realized with websockets. In the next section we present the implementation progress of the proposed framework in one of our on-going research projects in this field mobile data collection.

\section{INTEGRATION INTO THE LETS GO PROJECT}

In order to explore how the proposed ideas can be integrated into everyday educational practices, we have conducted a series of workshops with high school teachers. These activities took place in the fall term 2013 with 9 natural science teachers. We performed exploratory observational studies to determine the purpose for which educators want to use web and mobile technologies in their every day lessons. We provided teachers with a template so that they can write down learning scenarios in which they want to apply ICT in their lessons. The 9 teachers envisioned 22 scenarios. Out of these 22 scenarios, 15 were linked to data collection scenarios and 7 of those to get a better understanding of scientific methods. Since the majority of the scenarios that the teachers provided dealt with data collection, we have decided to select the LETS GO project (Learning Ecology with Technologies from Science for Global Outcomes) [14] as an ideal platform for our implementation. Since 2008 we have been working on the LETS GO project to design and deploy collaborative learning data collection activities by utilizing mobile and sensor technologies. Therefore, this project and related previous efforts fit very well with the content suggested by the teachers and LETS GO can serve as the ideal initial platform to implement the proposed web-based framework. However, in the current state, the different technological solutions available via the LETS GO system are lacking the possibility for educators to design their individual mobile applications for data collection activities. Thus, a developer has to do the implementation with the requirements provided by end-users. Also, the mobile application of the LETS GO project is designed only for Android devices and is not compatible with other devices running a different mobile OS. In order to tackle these problems, the first step of the proposed approach is the integration of a web-based authoring tool into the LETS GO software system in order to deploy web-based mobile applications. In the remaining of the section, we focus on the Authoring Tool and Mobile Application only.

\section{A. Authoring Tool}

With this tool, it is possible to easily compose data collection tasks for educators. A set of these data collection tasks is called a scenario. Since it is a web-based application, the access to the authoring tool is a web page. It is possible to login via the OAuth ${ }^{3}$ standard to provide access for users without the need to create a new account, since a majority of users already have an account supported by the OAuth standard. After the login, a teacher has the possibility to either create a new individual scenario or edit an already

\footnotetext{
${ }^{3}$ http://oauth.net/
} 
existing scenario. After choosing either to create or to edit a scenario, the teacher reaches the actual authoring tool. The user interface is divided into three parts: a panel to add new data collection tasks on the right hand side of the display; an overview about existing 'screens' on the left hand side; and an overview over the already created tasks in the middle. A screen in the authoring tool represents the information that is later displayed on one screen of the mobile device. It is possible to create and delete multiple screens. Figure 3 gives an overview of the interface of the authoring tool.

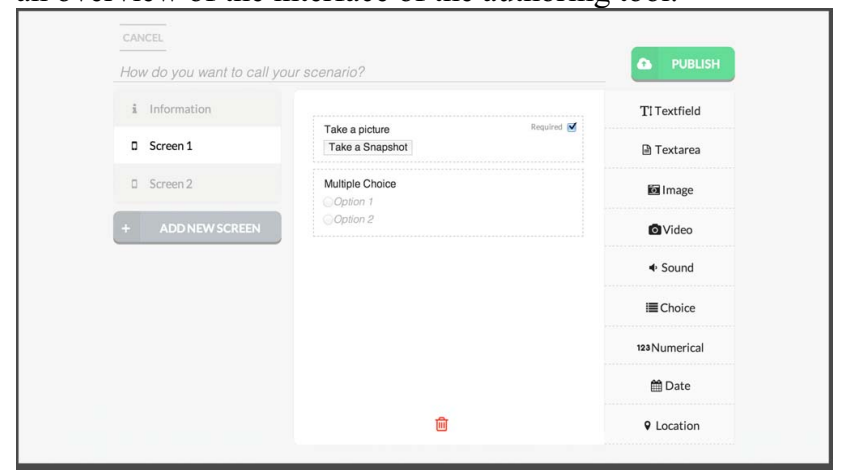

Figure 3. The authoring tool implementation

As shown in Figure 3, in the current state the following data tasks can be added: a text field to enter text information; for longer texts a text area; a numerical field to enter numerical data; the following media types: taking a picture, taking a video and recording sound; in addition, it is possible to add a date field and a location field that later captures the GPS coordinates of the mobile device.

These tasks can be added to the screen via drag and drop. It is possible to drag one task to the screen in the middle and afterwards, it is possible to rearrange the order of the tasks also via drag and drop. A task can be placed in different screens through dragging it to a screen on the left side. The publish button saves a scenario which is then available to be executed on mobile devices.

\section{B. Mobile Application}

After creating and saving a scenario using the authoring tool as described before, the scenario can be executed on a mobile device. Since it is a web application, it runs on a mobile device that has a browser with HTML5 support, regardless of its brand and operating system. After opening the application with the browser, an overview of existing scenarios is presented. After choosing a specific scenario, the previously designed tasks can be executed with the mobile device. In the current state, the web-application allows taking pictures and videos, recording sound and getting the GPS coordinates from internal sensors of a mobile device that has a HTML5 compatible browser installed and possesses these sensors.

\section{PROGRESS AND VALIDATION STRATEGY}

In this section, we present our validation plan in order to describe how our ideas will be implemented in practice. As mentioned before, we are working closely with an association of high schools in the Southeast of Sweden where additional activities will include hands on workshops with a set of prototypes. To evaluate their technological acceptance, we will conduct a study following Davis' Technology Acceptance Model [18]. This model fits our needs perfectly since it provides access to questionnaires with a specific focus on the Perceived Usefulness and the Ease of Use. We developed our own questionnaires, presented in Table 2 and Table 3 (following Davis' concept [19]), to gather data about the Ease of Use and Perceived Usefulness from the authoring tool and the mobile application. Those questionnaires are not identical with the one from Davis but adapted to the specifications of the presented work. The questions about the Ease of Use are the same in both questionnaires and are derived from [20]. All questions are rated in a 7-scale Likert scale [21].

Table 2. Questionnaire for the authoring tool

\begin{tabular}{|c|c|}
\hline Perceived Usefulness & Ease of Use \\
\hline \multicolumn{2}{|c|}{ The authoring tool ... } \\
\hline $\begin{array}{l}\text { Q1: ... allows me to } \\
\text { transform my ideas into } \\
\text { tasks. }\end{array}$ & $\begin{array}{l}\text { Q1:... has a set of } \\
\text { functionalities that are easy to } \\
\text { understand. }\end{array}$ \\
\hline $\begin{array}{l}\text { Q } 2: . . \text { hinders me deploying } \\
\text { mobile applications without } \\
\text { programming skills. }\end{array}$ & $\begin{array}{l}\mathrm{Q} 2 \text { :... has not a user-friendly } \\
\text { interface design. }\end{array}$ \\
\hline $\begin{array}{l}\text { Q3:... allows me to design } \\
\text { learning tasks for mobile } \\
\text { devices. }\end{array}$ & $\begin{array}{l}\text { Q3:... has a good description } \\
\text { of its sets of functionalities. }\end{array}$ \\
\hline $\begin{array}{l}\text { Q4: ... enables the design of } \\
\text { data collection for mobile } \\
\text { devices with internal sensors. }\end{array}$ & $\begin{array}{l}\mathrm{Q} 4: . . . \text { has interaction methods } \\
\text { that are not familiar to me. }\end{array}$ \\
\hline $\begin{array}{l}\text { Q5: ... makes it difficult to } \\
\text { deploy my scenario as a } \\
\text { mobile application. }\end{array}$ & Q5: ... performs as expected. \\
\hline & $6: \ldots$ is exhaus \\
\hline
\end{tabular}

Table 3. Questionnaire for the mobile application

\begin{tabular}{|c|c|}
\hline Perceived Usefulness & Ease of Use \\
\hline \multicolumn{2}{|c|}{ The mobile application ... } \\
\hline $\begin{array}{l}\text { Q1: ... allows me to collect } \\
\text { data with internal sensors. }\end{array}$ & $\begin{array}{l}\mathrm{Q} 1: \ldots \text { has a functionality that } \\
\text { is easy to understand. }\end{array}$ \\
\hline $\begin{array}{l}\text { Q2: ... hinders me entering } \\
\text { text or numbers. }\end{array}$ & $\begin{array}{l}\mathrm{Q} 2: . . \text { has not a user-friendly } \\
\text { interface design. }\end{array}$ \\
\hline $\begin{array}{l}\text { Q3:... allows me to execute } \\
\text { tasks outside the classroom. }\end{array}$ & $\begin{array}{l}\text { Q } 3: \ldots \text { has a good description } \\
\text { of its functionalities. }\end{array}$ \\
\hline $\begin{array}{l}\text { Q4:... allows me to execute } \\
\text { tasks outside the classroom. } \\
\text { complicates the execution of } \\
\text { learning tasks. }\end{array}$ & $\begin{array}{l}\text { Q4:... has interaction methods } \\
\text { that are not familiar to me. }\end{array}$ \\
\hline $\begin{array}{l}\text { Q5: Overall, I think such a } \\
\text { mobile application is helpful } \\
\text { to collect data. }\end{array}$ & Q5: ... performs as expected. \\
\hline $\begin{array}{l}\text { Q6:... helps me to better } \\
\text { understand a learning topic. }\end{array}$ & $\mathrm{Q} 6: . .$. is exhausting to use. \\
\hline
\end{tabular}

Based on the elaboration of the evaluation results, new requirements and improvements will be identified and will be applied to the refined version of coming prototypes. Afterwards, new activities with teachers and students will be carried out and the process repeats itself. This sort of cyclic 
prototyping will be repeated until no significant changes during our workshops will be discovered. Then a stable product is ready to get deployed. Figure 4 illustrates this approach.

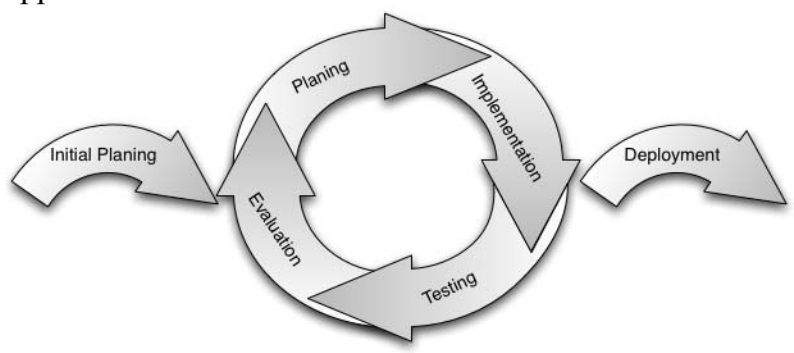

Figure 4. Cyclic prototyping

The benefit of collaborating with the network of schools is the definition of more requirements for a more flexible approach than the LETS GO environment. Requirements for a more flexible approach, which is not limited to data collection tasks but also can support a wider range of learning tasks, e.g. quizzes described by [22].

\section{FUTURE WORK}

The efforts described in this paper represent the initial steps towards an approach to formulate a domain specific software architecture that can serve as a common approach to develop software in the field of mobile learning. Despite the new opportunities mobile technologies bring to the educational field, software developers for mobile applications generally take a certain use case into consideration, based on a single scenario and the software is developed to fulfill the needs for just this case. However, as soon as the scenario differs to the one that fits to the application, the software development approach loses its validation. We will try to define a general software architecture that supports the flow mentioned above in an interoperable way.

In future iterations, we want to give end-users the possibility to design a variety of learning tasks and not only data collection tasks. One idea mentioned above is the addition of quizzes. We do not want to limit the approach and hence is why we will try to give end-users the possibility to design their own tasks. Thus, they can design their scenarios with a mixture of different tasks. In that way, endusers have more freedom in designing individual applications and are not limited to scripted scenarios with narrowed influence on the way a scenario is executed.

\section{REFERENCES}

[1] S. Ruth, "Is E-Learning really working? The trillion-dollar question," Internet Comput. IEEE, vol. 14, no. 2, pp. 78-82, 2010.

[2] M. Milrad, L.-H. Wong, M. Sharples, G.-J. Hwang, C.-K. Looi, and H. Ogata, "Handbook of Mobile Learning," Z. L. B. \& L. Y. Muilenburg, Ed. New York: Routledge, 2013, pp. 95-108.

[3] H. D. Mehlinger, "School reform in the information age," Phi Delta Kappan, vol. 77, pp. 400-407, 1996.
[4] J. Lave and E. Wenger, Situated learning: Legitimate peripheral participation. Cambridge university press, 1991.

[5] C. O'Malley, G. Vavoula, J. P. Glew, J. Taylor, M. Sharples, and others, "Guidelines for learning/teaching/tutoring in a mobile environment," 2005 .

[6] J. Farmer, D. Knapp, and G. M. Benton, "An elementary school environmental education field trip: Long-term effects on ecological and environmental knowledge and attitude development," J. Environ. Educ., vol. 38, no. 3, pp. 33-42, 2007.

[7] J.-L. Shih, H.-C. Chu, G.-J. Hwang, and others, "An investigation of attitudes of students and teachers about participating in a contextaware ubiquitous learning activity,” Br. J. Educ. Technol., vol. 42, no. 3, pp. 373-394, 2011.

[8] J. Bosch, "From software product lines to software ecosystems," in Proceedings of the 13th International Software Product Line Conference, 2009, pp. 111-119.

[9] T. Mikkonen and A. Taivalsaari, "Reports of the Web's Death Are Greatly Exaggerated," Computer (Long. Beach. Calif)., vol. 44, no. 5, pp. 30-36, 2011.

[10] J. Heer, F. B. Viégas, and M. Wattenberg, "Voyagers and voyeurs: supporting asynchronous collaborative information visualization," in Proceedings of the SIGCHI conference on Human factors in computing systems, 2007, pp. 1029-1038.

[11] P. Mulholland, S. Anastopoulou, T. Collins, M. Feisst, M. Gaved, L. Kerawalla, M. Paxton, E. Scanlon, M. Sharples, and M. Wright, "nQuire: technological support for personal inquiry learning," Learn. Technol. IEEE Trans., vol. 5, no. 2, pp. 157-169, 2012.

[12] G.-J. Hwang, C.-C. Tsai, C. Y. Chen, and others, "A context-aware ubiquitous learning approach to conducting scientific inquiry activities in a science park," Australas. J. Educ. Technol., vol. 28, no. 5, pp. 931-947, 2012.

[13] A. Giemza, L. Bollen, and H. U. Hoppe, "LEMONADE: field-trip authoring and classroom reporting for integrated mobile learning scenarios with intelligent agent support," Int. J. Mob. Learn. Organ., vol. 5, no. 1, pp. 96-114, 2011.

[14] B. Vogel, A. Kurti, M. Milrad, E. Johansson, and M. Mu ller, "Mobile Inquiry Learning in Sweden: Development Insights on Interoperability, Extensibility and Sustainability of the LETS GO Software System," Educational Technology \& Society (forthcoming)

[15] W. J. Krepel and C. R. DuVall, Field Trips: A Guide for Planning and Conducting Educational Experiences. Analysis and Action Series. ERIC, 1981.

[16] L. Cuban, Oversold and underused: Computers in the classroom. Harvard University Press, 2009.

[17] J. Zbick, "A web-based approach for designing and deploying flexible learning tools," in Current Trends in Web Engineering, 2013, pp. 320-324.

[18] F. D. Davis, R. P. Bagozzi, and P. R. Warshaw, "User acceptance of computer technology: a comparison of two theoretical models," Manage. Sci., vol. 35, no. 8, pp. 982-1003, 1989.

[19] F. D. Davis, "Perceived usefulness, perceived ease of use, and user acceptance of information technology," MIS Q., pp. 319-340, 1989.

[20] A. Giemza, L. Bollen, M. Jansen, and H. U. Hoppe, "A flexible unified architecture to support heterogeneous multi-device learning environments," Int. J. Mob. Learn. Organ., vol. 7, no. 3, pp. 210-223, 2013.

[21] R. Likert, "A technique for the measurement of attitudes.," Arch Psychol., vol. 22, no. 140, pp. 1-55, 1932.

[22] M. Jansen and S. Geisler, "About a Platform Independent Client for Mobile Quizzes in Moodle," in Proceedings of the 19th International Conference on Computers in Education, 2011. 